\title{
Correction to: CYP2E1-mediated oxidative stress regulates HO-1 and GST expression in maneb- and paraquat-treated rat polymorphonuclear leukocytes
}

\author{
Israr Ahmad ${ }^{1}$. Smriti Shukla ${ }^{1}$. Deepali Singh ${ }^{1,2} \cdot$ Amit Kumar Chauhan $^{1,2} \cdot \operatorname{Vinod~Kumar~}^{1,2} \cdot$ Brajesh Kumar Singh $^{1}$. \\ Devendra Kumar Patel ${ }^{1} \cdot$ Haushila Prasad Pandey ${ }^{3}$. Chetna Singh ${ }^{1,2}$
}

Published online: 19 July 2019

(c) Springer Science+Business Media, LLC, part of Springer Nature 2019

\section{Correction to: \\ Molecular and Cellular Biochemistry (2014) 393:209-222 \\ https://doi.org/10.1007/s11010-014-2062-y}

In the original publication of the article, the wrong $\beta$-actin blots were pasted in Figs. $1 \mathrm{~b}$ and 2c. The correct versions of Figs. $1 \mathrm{~b}$ and $2 \mathrm{c}$ are given in this correction.

The original article can be found online at https://doi.org/10.1007/ s11010-014-2062-y.

Chetna Singh

singhchetnaitrc@rediffmail.com

1 Council of Scientific and Industrial Research-Indian Institute of Toxicology Research (CSIR-IITR), Mahatma Gandhi Marg, Post Box- 80, Lucknow, Uttar Pradesh 226 001, India

2 Academy of Scientific and Innovative Research (AcSIR), New Delhi, India

3 Banaras Hindu University (BHU), Varanasi, Uttar Pradesh 221 005, India 
Fig. 1 b Effect of MB and/or PQ on CYP2E1 and GSTA4-4 protein expression in rat $\mathrm{PMNs}$ following 1, 2 and 3 weeks of exposure. Upper panel shows representative western blots of CYP2E1, GSTA4-4 and $\beta$-actin protein expression and lower panel shows densitometric analysis of the same. $(n=4)$ $(* p<0.05, * * p<0.01$ and $* * * p<0.001$ as compared with control; ${ }^{\#} p<0.05,{ }^{\# \#} p<0.01$ and ${ }^{\# \# \# p} p .001$ as compared with MB treated groups; ${ }^{\$} p<0.05$ as compared with PQ treated groups). (Control, maneb-treated, paraquattreated and maneb+paraquat treated groups are represented as $\mathrm{Con} / \mathrm{C}, \mathrm{MB} / \mathrm{M}, \mathrm{PQ} / \mathrm{P}$ and $\mathrm{MB}+\mathrm{PQ} / \mathrm{MP}$ respectively) b
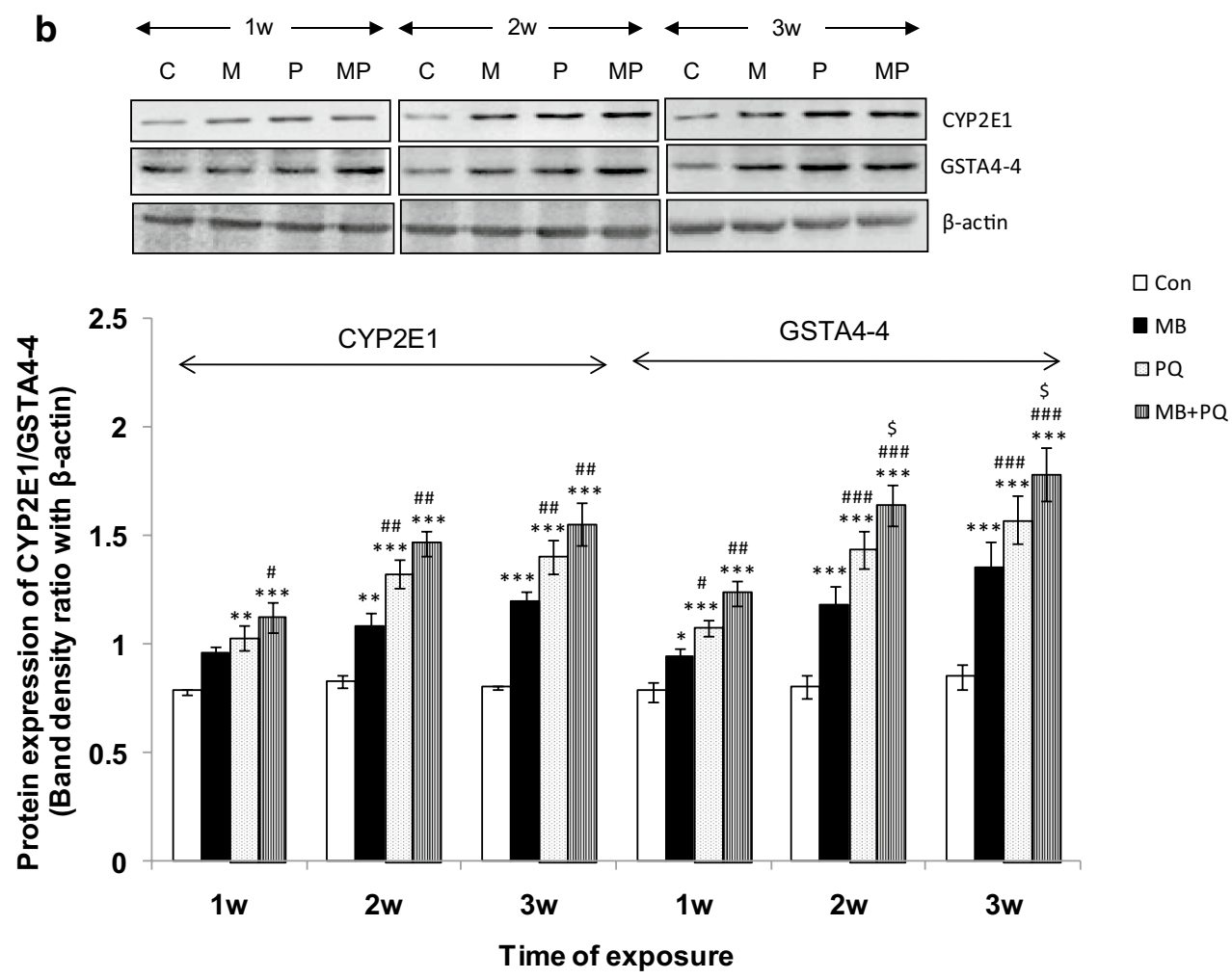

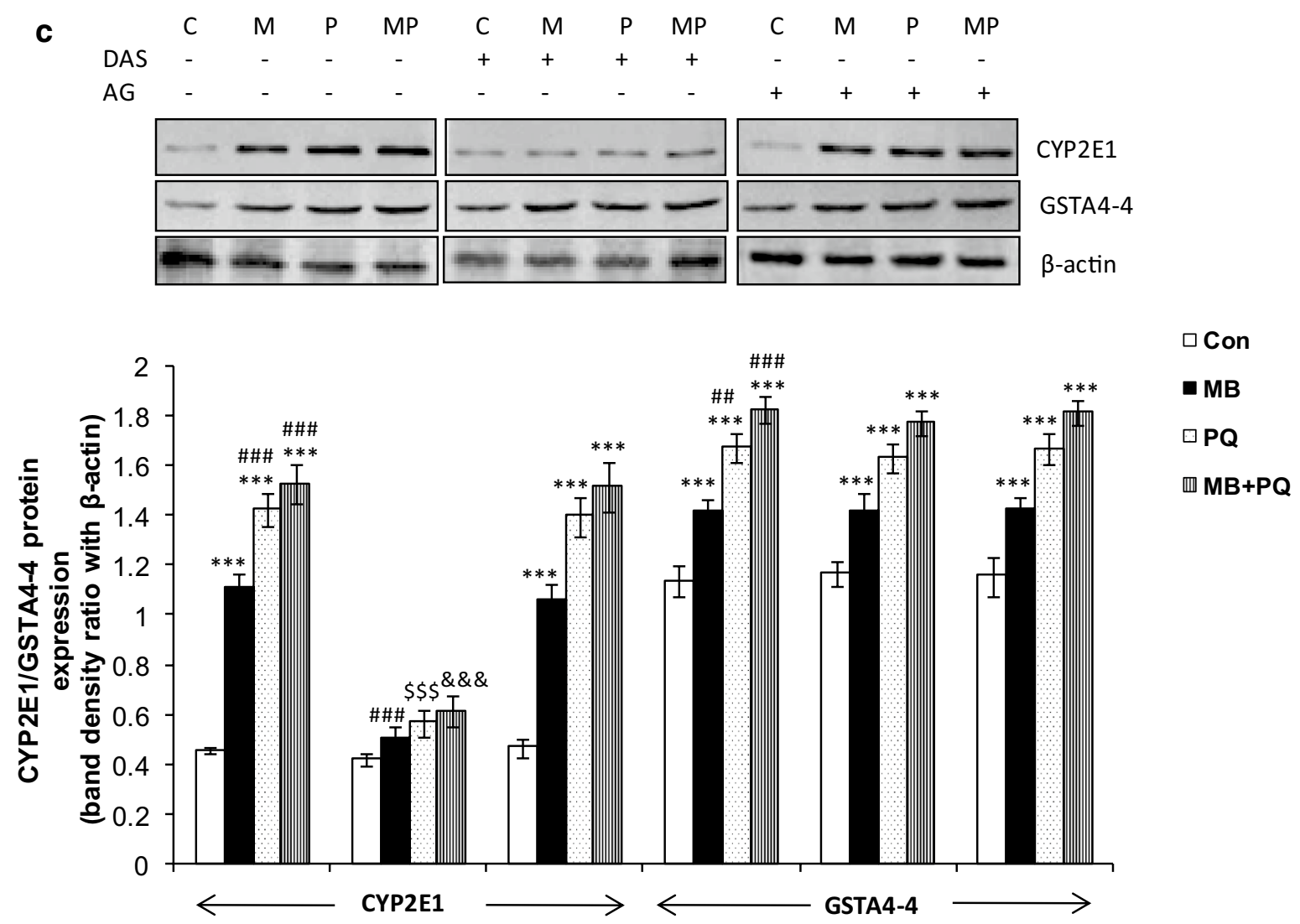

Fig. 2 c Effect of DAS and AG pre-treatment on MB and/or PQinduced increase in CYP2E1/GSTA4-4 protein expression following 2 weeks of exposure. Upper panel shows representative western blot of CYP2E1/GSTA4-4/ $\beta$-actin and lower panel shows densitometric analysis of the same. $(n=4)(* * * p<0.001$ as compared with control; ${ }^{\# \#} p<0.01$ and ${ }^{\# \# \# p} p 0.001$ as compared with MB treated

Publisher's Note Springer Nature remains neutral with regard to jurisdictional claims in published maps and institutional affiliations. groups; ${ }^{\$ \$} p<0.001$ as compared with $\mathrm{PQ}$ treated groups and $\& \& \& p<0.001$ as compared with MB+PQ treated groups). (Control, maneb-treated, paraquat-treated and maneb+paraquat treated groups are represented as Con/C, MB/M, $\mathrm{PQ} / \mathrm{P}$ and $\mathrm{MB}+\mathrm{PQ} / \mathrm{MP}$ respectively) 